\title{
El Tocotín Expresión de Identidad
}

El Tecotín o mitote, la danza azteca festiva, aparece con tal frecuencia en las obras dramáticas de la Nueva España que permite seguir su trayectoria desde los primeros autos misioneros hasta Sor Juana. ${ }^{2}$ El hecho de que esta danza se incluyera ya en las primeras obras dramáticas de la Colonia se suele interpretar como manifestación de ufania de quienes experimentaban en si mismos una resonancia y personal aprecio por la cultura precortesiana, que no se prestaba fácilmente a la representación dramática ni a su incorporación en las formas clásicas del teatro español. Su sola presencia es indicio de la simbiosis cultural.

La primera noticia que tenemos del tocotín, fuera del drama didáctico compuesto por los misioneros, es el dramático y devoto Auto y Triunfo de la Virgen y Gozo Mexicano (1620), cuyo autor, Francisco Bramón, se empeña en recalcar lo de "gozo mexicano", al poner el tocotín en lugar de la "despedida", que era más usual." En las acotaciones se encuentra una de las más completas descripciones de la danza e instrumentos que la acompañan. Ya casi al fin del drama dos ciudadanos se aprestan a cantar las alabanzas de la Virgen, y en ese momento un tropel de muchachos en atuendo azteca se presentan con of rendas florales y portando instrumentos musicales. Les siguen seis caciques vestidos con calzas bordadas de oro y calzados con sandalias adornadas del mismo metal; cada uno de ello lleva un escudo sobre el cual aparece en relieve el águila sobre la tuna. Al fin aparece como personaje alegórico el Reino Mexicano, al igual que los caciques cubierto además de tilma de plumas y oro y tocado con penacho de plumas multicolores. Los siete hacen teve-

1 Los misioneros adoptaron el tocotín ya en los primeros tiempos. Posteriormente 10 extendieron al Norte hasta Baja California; todavia en fecha tan posterior como 1699, Salvatierra narra su llegada a Loreto e incluye una versión del tocotín que vio representar. V. Francisco Marla Piccölo, S.J., Informe del estado de la nueva cristiandad de California, edición, estudio y notas por Ernest Burrus, S.J., Madrid, Ediciones José Porrúa Turanzas, 1962, p. 7.

${ }^{2}$ Francisco Bramón, Auto del triunfo de la Virgen y gozo mexicano (1620), edición de Agustín Yáñez. México, UNAM, 1945. 
rencia al trono de la Virgen y comienzan su danza acompañados por los músicos. ". . sacaron diversidad de instrumentos que usan en esta danza, entre los cuales aquél que es más necesario se llama teponaztle, que es de palo, y todo de una pieza, muy bien labrado, hueco, y sin cuero ni pergamino por de fuera, con cierta hendedura o muesca por lo alto; tócase con palillos, aunque son los extremos delicados, por ser de algodón; de otro instrumento usan, que es mayor que éste, alto más que hasta la cinta, redondo, hueco, entallado por de fuera y pintado, en su boca tiene un ancho parche de cuero de venado, bien curtido y estirado, que, apretado, sube, o flojo, abaja el tono; tócase con las manos, aunque con trabajo. Concertados éstos y otros instrumentos, dieron los siete principio a una vistosa danza, que llaman los mexicanos netotiliztle, y en nuestro vulgar, mitote o tocotín; es danza que para relación o escrita no tiene gracia y donaire, que le comunican aquellos que diestramente deleitan en ella con sus agradables vueltas, reverencias; entradas, cruzados y paseos, como lo hicieron maravillosamente estos siete mexicanos... "3.

En tanto que aquellos danzan, otros entonan a coro los versos que ron siete coplas escritas en hexámetros.

Bailad, mexicanos;
suene el tocotín
pues triunfa María
con dicha feliz.
Cantad aleluyas
a Dios, que sin fin,
pues triunfa María
con dicha feliz

A esta altura el drama ha asumido una nota lírica, en lenguaje poético directo y claro, sin trabas de retruécanos culturanos o conceptistas, para llegar a un armonioso final en una atmósfera de jubiloso triunfo. Los instrumentos, el vestuario, los caciques y el Reino de México, al mismo tiempo que simbolizan al Nuevo Mundo, dan al conjunto un am. biente de ese mundo con su exótica cultura. Hay que conceder que, con excepción de las primeras palabras, 10 mismo pudieron haberse escrito esos versos en México que en España, pero música, danza y caciques que "son nobles y de buen linaje", añaden la atmósfera peregrina y exótica.

4 Ibid., D. 58. 
Sor Juan Inés de la Cruz invierte el proceso usando el tocotín como poema introductorio a su Loa Para el Auto Divino Narciso. ${ }^{5}$ El tono, además, es de un festivo regocijo, aun cuando el tocotín ha sufrido una obvia transformación estética dictada en parte por la finalidad del auto. En último término el tocotín no es más que una breve nota de alegre introducción a una loa cuyo tema versa sobre los antiguos sacrificios aztecas en cuanto presagiaban el Sacrificio Eucarístico Cristiano. Para la loa se han alterado ligeramente la rima y estructura de los versos, pero la introducción de la danza es un rasgo feliz que establece la atmósfera para la descripción de la festividad del "gran dios de las semillas". Tanto en esta loa como en la que precede a $E l$ Cetro de José es en donde Sor Juana parece vibrar más entrañablemente con el indígena mexicano y en donde mejor expresa la estima por su cultura. $Y$ esta simpatía se hace evidente en otros tocotines, incluso uno en náhuatl, los que sin duda deleitaban su oido tan sensible a toda melodia, ya fuera en verso, ya en música. A pesar de la versión hispanizada que tiene el tocotín en la Loa Para el Auto El Divino Narciso, es quizá más tradicional que la que Bramón incluyó en su auto. Ya en las primeras líneas, Sor Juana hace referencia al mito azteca de los hijos del sol:

\author{
Nobles mejicanos \\ cuya estirpe antigua \\ de las claras luces \\ del Sol se origina. ${ }^{6}$
}

Alfonso Méndez Plancarte supone que esta referencia procede de la Historia Eclesiástica de Mendieta, a través de la edición de 1615 de la Monarquia Indiana de Torquemada, en la que se cuenta el mito del sol que dispara una flecha. ${ }^{7}$ Tan posible es, sin embargo, y con mayores visos de probabilidad, que la tradición misma hubiera sobrevivido en las danzas rituales aztecas que eran familiares a Sor Juana. Evidente confirmación se encuentra en los tocotines que se danzaron en 1628 y 1640 en el Colegio Máximo de San Pedro y San Pablo.

Matías de Bocanegra había escrito la Comedia de San Francisco de Borja que se representó en 1640 para celebrar la llegada de Diego López de Pacheco, Marqués de Villena y Duque de Escalona, el nuevo vi-

5 Sor Juana Inés de la Cruz, Obras completas, edición, prólogo y notas Al. fonso Méndez Plancarte, México, Fondo de Cultura Económica, 1955, vol. II, p. 3 .

6. Ibid, p. 3 .

7 Ibid., p. 503. 
rey de Felipe IV. ${ }^{8}$ Como era costumbre en tales ocasiones, se hacian versos alusivos al huésped tanto al comienzo como al final de la obra. Una vez más, aquí también el tono es festivo y la ornamentación rica y exótica. Al par que la intención de halagar al virrey, se expresa el orgullo: por la hermosura de México, y si bien, en muestra de vasallaje, con evo. caciones cultuales se equipara al visitante con el sol en su cenit, aparece bien definida una expresión de identidad mexicana, de que se es otra nación y un pueblo distinto:

Como veremos luego, no es esto una mera pretención de leer en un texto temprano actitudes que no surgieron sino hasta más tarde. Lo que aparece claro desde tiempos de Bramón hasta Sor Juana es que el tocotín expresaba una comprensión simpática mezclada de ufanía por una cultura que no era europea. Pero la manifestación mảs fuerte de estos sentimientos y en donde la identidad mexicana se percibe ya sin ambigüedades es el tocotín que se danzó en el Colegio Máximo de los jesuítas en México en 1628.

Para decirlo en pocas palabras la ocasión era delicada y al mismo tiempo preñada de esperanzas gravemente amenazadas por recientes desastres. Un nuevo arzobispo, Francisco Manso y Zúñiga, había llegado en abril a ocupar la sede de México. ${ }^{10} \mathrm{El}$ nuevo virrey, Rodrigo Pacheco y Osorio, Marqués de Cerralvo, le había precedido cuatro años antes. Ahora bien, la última vez que habían coincidido en México un arzobispo y un virrey, la apenas disfrazada rivalidad entre ambos había terminado en el tumulto de 1624, el saqueo del palacio virreinal y el exilio de ambos personajes.

Así, pues, México tenía de nuevo sus dos señores, el espiritual y el temporal; el espiritual acababa de llegar y aunque estaba destinado a una destitución eventual por diferencias con el que sería sucesor de Cerralvo, esto estaba aún por venir; lo que estaba presente era la memoria de 1624, los precios fluctuantes de los granos, la peor sequía de la historia seguida por las inundaciones de 1627. Como si fuera poco, la rápida disminución de la población indígena del Valle de México se había hecho

\footnotetext{
8 José J. Arrom, "Una desconocida comedia mexicana del siglo XVII", Rewista Iberoamericana, XIX, no. 37, oct. 1953, Pp. 82-3.

9 Sali, mexicanos baila el tocotín que al sol de Villena tenéis en zenith ibid., p. 93.

10 Mariano Cuevas, Historia de la lglesia en México, El Paso, Editorial Revista Católica, 1928. El tomo II, p. 123, señala el 12 de abril de 1628 como la fecha en que Manso ocupó su sede.
} 
evidente a todos, excepto al observador más obtuso, y el sistema del repartimiento estaba evolucionando hacia la hacienda con la secuela de deudas que pesaban sobre el común de los peones indios. ${ }^{11}$ Este era, pues, el fondo sobre el que se proyectaba la recepción festiva que se haría al nuevo arzobispo en abril de $1628 ;^{12}$ y aun tal vez latente en el recuerdo de los jesuítas allí reunidos, bullía la sarcástica defensa que en nombre de ellos se había hecho para librarlos de la condenación en época del último motín. "Los padres de la Compañía, con su singular prudencia, desean siempre no dejar descontento a nadie; $y$ esto intentaron en este caso, si bien no parece que lo consiguieron". ${ }^{13}$

Ahora, quizá había llegado la ocasión de hablar claro y de tomar posiciones, y esto precisamente hicieron. Presentaron la Vida de San Ignacio, comedia en cinco actos de teatro colegial y de tradición jesuítica, en la que, al final, uno de los personajes, un ángel, daba la despedida. ${ }^{14}$ No son de sorprender en lo más mínimo los juegos de palabras y las figuras literarias que el apellido de Manso proporcionó a los versificadores barrocos. La despedida es semejante a los versos introductorios, pero hay un cambio del tono festivo a la melancolía y la nostalgia. En marcado contraste con los versos laudatorios de la introducción, el ángel se dirige al arzobispo en la siguiente décima:

Yo como sé lo que el cielo
estima pobres humildes
y que del mundo las tildes
son los indios de este suelo,
quiero inclinar mi alto vuelo
a su humilde tocotín;
que por los indios al fin
puestas las alas en cruz

11 Charles Gibson, The Aztecs under Spanish Rule, Stanford, 1964. Cualesquiera que sean los datos estadísticos que se elijan, no hay duda de que la población indígena disminuyó rápidamente entre 1620 y 1650. Véase pp. 136. 141; Appendix IV, pp. 448-451 acerca de la crisis creciente que representaban los peones cargados de deudas, véase pp. $248-249$ y la nota p. 534 .

12 Cuevas, op. cit. y los versos dedicados a Manso señalan abril como el mes en cuestiớn.

13. Francisco Javier Alegre, S.J., Historia de la Compañia de Jesus de Nueva España, nueva edición por Exnest Burrus, S.J., y Félix Zubillaga, S.J., Roma, Institutum Historicum S.J., 1958, vol. II, p. 363 .

14 Vida de San Ignacio, Biblioteca Nacional de México. Ms. 244 (588). Actualmente preparo de esta obra una descripción detallada que más tarde formará parte de un libro acerca del teatro escolar jesuítico en México. 
eclipsó su hermosa luz

el Divino Serafín. ${ }^{15}$

Tras presentar al obispo este no muy sutil recordatorio acerca de los humildes y pobres, el tocotín comienza a incorporar dos temas: el origen: solar de los aztecas y el reconocimiento, en la persona del arzobispo, de aquél que había de llevar el mito a su plenitud, ya que es el padre de aquéllos. Como se verá, en el fondo es la misma técnica que habrá de emplear Sor Juana; el mito pagano que presagia una realización cristiana. Los danzantes son de nuevo caciques, y empiezan:



$Y$ asi sigue la danza, pero cerca de su mitad irrumpe de nuevó el ángel en versos del mismo corte, pero en los cuales, en vez de las gozosas palabras "bailad", "cantad" o "salid", comienza un treno:

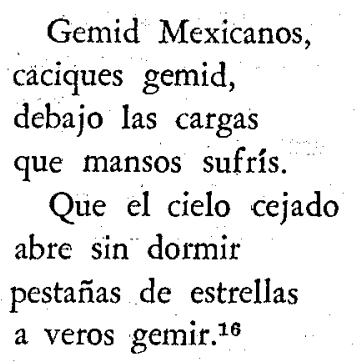

Asombrado el ángel pregunta "¿Quién os carga así?" y, fiel a la corriente ascética del S. xviI, encuentra un paliativo o quizá un consuelo: puesto que los indios sufrían por amor de Dios, podían encontrar en ello razón para alegrarse. Pero la cuestión no es tan simple, porque después

15 Ibid., fol. 91 v. y 92 r.

16 Ibid., $92 \mathrm{r}$. 
de aludir a los trágicos sucesos de la Navidad de 1624 y de encontrar pro: mesas de un futuro más benigno, el tono cambia nuevamente para explayarse esta vez en otro tema, el de la disminución de la población indigena:

\author{
Nuestros bailes daban \\ cuando yo nací \\ Todas se volvieron \\ plumas de neblí \\ sobre indios pelados \\ gavilanes mil. \\ Cuarenta mil indios \\ solían salir \\ en México al baile \\ hoy no hay cuatro mil. \\ De hoy en cien años \\ oirán decir: \\ "Cómo eran los indios?". \\ "No sé, no los ví." 18
}

En estas coplas se encuentra algo más que una mera condenaciỏn de la rapacidad que había reducido el número de indios relegándolos a una condición de miseria y penuria; presentes están también los presagios que inquietaban a hombres como Mendieta, Dávila Padilla y Torquemada. En su Memorial, Fray Toribio de Betanzos había sostenido que la población indígena estaba destinada a desaparecer. Las razones que aduce no favorecen ni a los indios ni a la idea que el fraile se había formado de la justicia de Dios, pero tal vez pudieron haber tranquilizado a los españoles que se veían en apuros por encontrar algún medio de impedir la desaparición de los indios. Otros cronistas, tanto franciscanos como dominicos, rechazaban el razonamiento de Betanzos, aunque coincidieran en admitir que los indios parecían destinados a desaparecer en virtud de algún decreto divino; Torquemada, por su parte, se hace eco de Betanzos en lo de que la última causa de la disminución de los indios es un castigo divino, más no así Dávila Padilla ni Mendieta. ${ }^{18}$ Este último,

1793 v. 94 r. Es interesante comparar estos números con las estadísticas que presenta Gibson, op. cit., pp. 139; 141 y 142 .

18 Véase John Leddy Phelan, The Millenial Kingdom of the Franciscans in the New World, University of California Press. 1956, pp. 90-92. 
en su enfoque cuasi místico, deparaba el castigo a los españoles y el premio a los indios.

Al igual que Dávila, Torquemada había publicado su Monarquía lndiana trece años antes de la llegada de Manso, y su tesis pudo of recer, y quizá of reciera, una fuerte tentación a los señores espirituales y temporales, acosados como estaban por tantos problemas, de considerar la desaparición de los indios de manera fatalista. Con todo, el tono de las coplas arriba citadas no es de pesimismo místico, y aunque, al igual que Mendieta, culpan a la avaricia, rechazan sin embargo el pesimismo para atender nuevamente a la idea de los primeros franciscanos acerca del milenario reino indigena. ${ }^{19}$ Esto no es mera conjetura, ya que se expresa el optimismo en una nueva profecía, que se entona como contraparte del triste estado antes descrito:

\author{
Bailemos caciques \\ que no será así \\ pues del sol colgada \\ nuestra águila ví.
}

Y luego aparece, en forma ligeramente modificada, el prometido Quezalcóatl, quien del polvo de huesos amasado en sangre y vivificando por el sol, moldea una nueva familia humana:

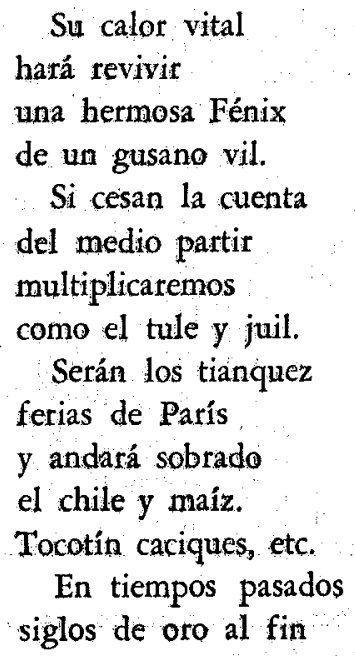

19 lbid., pp. 99-10s. 


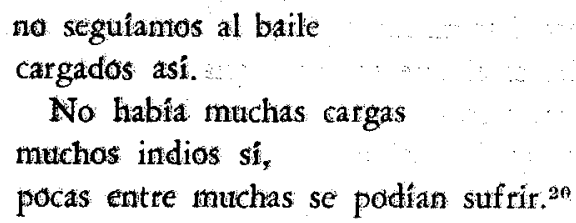

La sucesiôn de contrastes aumenta el efecto del verso: ayer los indios podian soportar las cargas, hoy ya no pueden sufrirlas; se compara el trágico presente con el dorado pasado y se logra un contraste implicito, con sobretonos emocionales, gracias a la repetición del estribillo "Toco. tin Caciques". Porque si los caciques eran todavía "Nobles de buen liraje", hacia mucho que habian dejado de ser un sector efectivo de la sociedad y eran más un recuerdo nostâlgico y a veces patético de glorias pasadas. ${ }^{21}$ Se hacía depender del sol la profecia del reino futuro. Del sof habia de recibir el águila los rayos vivificantes; y el sol era Manso, quien habría de hacer que este amable Fénix surgiera del polvo y la ceniza a una nueva vida.

No sólo los versos estaban planeados para producir su efecto, sino que también lo estaba el escenario. Porque en él estaban pintados, en combinación, el sello de la ciudad de México con el escudo de armas del arzobispo que aparecía sobre el pecho de águifa. Y como de todo aparecía la divisa renouabitur iuuentus tua, era obvio que de Manso y Zún̈iga mucho dependía y se esperaba.

El fuerte sabor didáctico en el teatro jesuitico escolar no es de sorprender, sino todo lo contrario; lo que no es usual es que se den lecciones a un arzobispo de modo tan público y a las dos semanas de su arribo; $y$ es sorprendente la franqueza del tono, aun haciendo concesiones al retruécano barroco. Pero, por otra parte, había un sentimiento de ur. gencia que debió haber penetrado a los jesuitas.

Sorprende también el sentido de mexicanidad que tenían esos jesuítas; siempre se habla de México, nunca de Nueva España; al glosar la divisa renouabitur se refieren a sí mismos como a la juventud de México; y más de un siglo después, los jesuitas mexicanos exilados, al esforzarse por interpretar el Nuevo Mundo ante Europa, darán marcadas muestras de una identidad que algunos han considerado como la primera agitación del espíritu nacionalista. Y aún hubo quienes, como Clavijero, llegaron a tomar simplemente como sinónimos al período de la Antigüedad Clási-

20 Op. cit., $94 \mathrm{r}$.

21 Gibson, op. cit., pp. 160-163 para lo de la decadencia del cacícazgo. : 
ca y la Epoca Azteca. Ese mismo espiritu, embrionario quizá en la forma, pero ya reconocible, es el que aquí se agita en 1628 , $Y$ esta simpatía $y$ orgullo por la cultura azteca se ha de ver en función de la formación que recibían los estudiantes del Colegio Máximo; la mayouría de ellos habían sido tempranamente docttinados en la estima y en el esfuerzo por comprender esa cultura ya desde los días de su noviciado en Tepozotlán. La insistencia en que los novicios dominaran las dos principales lenguas, el Náhuatl y el Otomí, está bien documentada. ${ }^{22}$ Tepozotlán, además de noviciado, era también colegio para la educación de jóvenes indios. Tanto énfasis se daba a que los jesuítas llegaran a ser bilingües y se familiarizaran con la cultura indígena, que sólo aquellos que fueran competentes en ambas lenguas indígenas podrían ser promovidos a ser rectores del colegio. ${ }^{23}$ Así, pues, junto con la formación intelectual que recibían los estudiantes de San Pedro y San Pablo, tanto la constante tradición de interés y cuidado por el indio como la reciente publicación de la Monarquía Indiana y la llegada del arzobispo, of recieron la oportunidad para una de las primeras y más fuertes expresiones de aspiraciones mexicanas.

Loyola University of Los Angeles.

THOMAS HANRAHAN; S. J.

22 Alegre, passim.

23 lbid., vol. II, p. 650. 